\title{
Child Pedestrian Injury in an Urban Setting: Descriptive Epidemiology
}

\author{
Charles DiMaggio, M.P.H., M.Phil., PA-C ${ }^{1,2}$ \\ \& \\ Maureen Durkin, Ph.D., Dr.P.H. ${ }^{2,3,4}$
}
${ }^{1}$ Department of Emergency Medicine Mt. Sinai Services Elmhurst Hospital Center
${ }^{2}$ Division of Epidemiology, Mailman School of Public Health, Columbia University
${ }^{3}$ Sergievsky Center, College of Physicians \& Surgeons, Columbia University
${ }^{4}$ Epidemiology of Brain Disorders Unit, New York State Psychiatric Institute

\section{Correspondence:}

Charles DiMaggio, MPH, PA-C

Department of Emergency Medicine

Elmhurst Hospital Center

79-01 Broadway

Elmhurst, NY 11373

Phone: (718) 334-3050

Fax: (718) 334-3015

Email: CJD11@Columbia.edu 
Child Pedestrian Injury in an Urban Setting:

Descriptive Epidemiology 


\section{ABSTRACT}

This study describes the epidemiology of pedestrian injuries to children and adolescents (ages <20) in an urban setting, providing analyses of environmental and pedestrian variables. Anonymous data were obtained for all motor vehicle crashes occurring in New York City over a 7-year period (1991-1997). Among 693,283 crashes, 97,245 resulted in injuries to 100,261 pedestrians of whom 32,578 were under age 20 . Using census counts for the denominator, the overall incidence of pediatric pedestrian injuries was $246 / 100,000$ per year, and the case fatality rate was $0.6 \%$. Incidence rates peaked in the 6-14 year age group, and showed a modest annual decline during the study period. Younger children were more likely to be struck mid-block and during daylight hours, whereas adolescents were more likely to be struck at intersections and at night. For younger children, there was a sharp peak in incidence during the summer months. Road and weather conditions did not appear to affect injury risk. These results help identify priorities for child pedestrian injury prevention and education, inform public health policy, and direct emergency medical health services resource allocation. (words=195)

Key words: Injury, pedestrian, pediatric, epidemiology 


\section{INTRODUCTION}

Motor vehicles pose a threat to the health of children. Pediatric pedestrians are particularly at risk of critical injury. In 1985, an estimated 50,000 children in the United States were struck by cars; 1,800 died. ${ }^{1}$ This $3.6 \%$ case-fatality rate varied from a low of $1 \%$ for the oldest children, to $9 \%$ for the youngest. ${ }^{1}$

Although there has been a $43 \%$ decline in pedestrian death rates since $1975^{2}$, child pedestrian injury (CPI) continues to rank among the most serious childhood diseases. In New Zealand, pedestrian injuries kill twice as many children as leukemia and 5 times as many as all infectious diseases combined. ${ }^{3}$ In the United States in 1997 there were 2,098 motor vehicle-related deaths in children younger than 13 years old, of which 506 were pedestrian fatalities.

Emergency departments bear the brunt of this onslaught of injury. In 1996 there were 163,000 emergency department visits for pedestrian injuries for all ages. ${ }^{4}$ In areas of New York City from 1989 to 1995, an estimated 127/100,000 pediatric population suffered pedestrian injuries severe enough to result in hospital admission or death. ${ }^{5}$ Pedestrian injuries account for $61 \%$ of all pediatric trauma admissions to US hospitals. ${ }^{1}$ They represent $34 \%$ of all pediatric critical care admissions. ${ }^{6}$ Younger children are at increased risk ${ }^{7}$ with a peak between ages 6 and $9 .{ }^{8}$ Males are at increased risk for injury, ${ }^{19}$ and are twice as likely to be killed if injured. ${ }^{10}$

The aim of the following study is to describe the epidemiology of pediatric pedestrian injury in an urban setting. It includes analyses of environmental, pedestrian, vehicle and driver related variables. The results are intended to help identify priorities for prevention and education, inform public health policy decisions, and direct emergency medical health services resource allocation. 


\section{Study Design}

\section{METHODS}

A descriptive, population-based, study of child pedestrian injury in New York City from 1991 to 1997 was undertaken. A database of all motor vehicle crashes involving pedestrians, based on forms MV-104AN, filed by the New York City Police Department with the New York State Department of Motor Vehicles was categorized by police precinct. New York State Vehicle and Traffic Law, sections 600 to 604 , requires the police to investigate and report motor vehicle crashes resulting in death, personal injury or property damage.

The accident records file is composed of a "header record" containing data common to the entire accident, such as date, location, and class of crash; a "vehicle trailer record" containing data on each individual vehicle involved in the crash; and an "occupant trailer record" containing data on the individuals involved in the crash, including drivers and pedestrians. Information on interpreting accident record files was obtained from the New York State Department of Motor Vehicles and the National Highway Traffic and Safety Administration. ${ }^{11} 12$

\section{Population and Study Site}

The unit of analysis for the study was the individual child, based on a universe of child pedestrians in New York City during the study period. An injured child was defined as an individual under the age of 20 who either resided in or visited New York City during the period under study and for whom a New York City Police Department form MV-104AN had been filed with the New York State Department of Motor Vehicles. Approval for this study was obtained from the ColumbiaPresbyterian Medical Center Institutional Review Board.

\section{Experimental Protocol}

The stages of data reduction began with the universe of 693,283 motor vehicle crashes in New York City between 1991 and 1997. Since multiple pedestrians may be involved in a single crash, separate person and incident files were examined and compared. 97,245 pedestrian incidents involving 104,946 injured people were identified; 4685 (4.5\%) of the injuries were missing an entry for pedestrian age and were excluded from analysis. Of the remaining 100,261 injured people, 32,578 were under the age of 20 years. This constituted the study population. Population counts used to compute incidence rates were obtained from the 1990 U.S. Census.

\section{Measurements}

Analyses are presented for the following 4 age categories: under 5 years old, 5 to 9 years old, 10 to 14 years old, 15 to 19 years old. These conventional census 
age categories correspond to some extent with behavioral, anatomical and physiological differences observed across pediatric age groups.

Injury Severity was based on the following State of New York Department of Motor Vehicles descriptions: ${ }^{13}$

1) "Fatal"

2) "Severe" injuries include severe lacerations, broken or distorted limbs, skull fractures, crushed chest, internal injuries, unconscious when taken from the crash scene, unable to leave crash scene without assistance.

3) "Moderate" injuries include lump on the head, abrasions, and minor lacerations.

4) "Mild" or no injuries include momentary unconsciousness, limping, nausea, hysteria and complaint of pain with no visible injury.

Investigating police officers make these assessments rather than medical personnel, although for severe and fatal injuries the police assessments are informed by interviews with medical personnel.

\section{Data Analysis}

Chi square for trend was conducted using Epi Info version 6.04. ${ }^{14}$ Other statistical analyses were carried out using SPSS version 9.0. ${ }^{15}$ Statistical significance was set at $5 \%$. To investigate the pattern of weekends vs. weekdays injuries, odds ratios and $95 \%$ confidence intervals were calculated for the association of age group with weekend vs. weekday injuries. Average yearly incidence rates were calculated by dividing the total number of injuries or fatalities by 7 (the number of years in the study period) then dividing this number by the population of interest. 


\section{RESULTS}

\section{Incidence, Mortality and Case-Fatality}

The overall yearly injury rate of $245 / 100,000$ varied from a low of 92.9 for the youngest pedestrians to a high of 333.1 for 5 to 9 year olds. Fatality rates were highest for the 5 to 9 year olds (1.6/100,000 population), but the case fatality rate indicated that pedestrians under the age of 5 were at greater risk of death when injured. (Table 1)

\section{Trends}

During the study period, there was a statistically significant decline in the absolute number of pediatric pedestrian injuries. $\left(X^{2}\right.$ trend $\left.=1396.154, p<0.00001\right)$ The 15 to 19 year old subgroup showed little change. These trends are illustrated in Figure 1.

\section{Seasonality}

The total frequency of injuries in the 5 to 9 year old group increased sharply in the summer months. There was a similar, but less marked, pattern for 10 to 14 year olds. (Figure 2)

\section{Day of Week, and Light Conditions}

As seen in table 2, most pediatric pedestrian injuries occurred on Fridays. For all three age groups, injuries occurred less commonly on weekends, with Sunday less so than Saturday. This pattern was most prominent among 10 to 14 year olds.

While weekday injuries predominated, Figure 3 illustrates that the proportion of injuries occurring on weekends increased during the summer months. By contrast, weekday injuries become more common during the school months. This pattern is more pronounced for younger pedestrians.

\section{Light Conditions}

Overall, $67.5 \%$ of pediatric pedestrian crashes occurred during daylight hours and $17.1 \%$ occurred after dark on a lighted road. But, for the youngest pedestrians, $74.1 \%$ took place during daylight hours, and only $10.2 \%$ took place after dark. For the oldest pediatric population, 53.4\% occurred during daylight hours, and $29.3 \%$ occurred after dark on a lighted road. Dark unlighted roads played little role for any age group, averaging about $0.7 \%$ of injuries. Few $(1.2 \%)$ of crashes occurred at dawn, and about 5 to 6 percent of injuries occurred at 
dusk. Again, these results were statistically significant. $\left(X^{2}=1403.836 \mathrm{df}=10\right.$ $p<0.0001$ )

\section{Age and Gender}

The age distribution for injured pediatric pedestrians shows a peak incidence in the 6-14 year age group. (Figure 4)

Males predominated across all age categories, but the gender difference was the most pronounced among the youngest children (Figure 5). These differences were statistically significant $\left(X^{2}=317.113, \mathrm{df}=2, \mathrm{p}<0.0001\right)$.

\section{Intersections, Traffic Controls, Pedestrian Actions}

Overall, most injuries occurred at intersections; but, for the younger pedestrians, intersections account for a minority of incidents. The older the child, the more likely the incident occurred at an intersection. These proportions, which are presented in Figure 6, were found to be statistically significant. $\left(X^{2}=961.5\right.$, df $=$ $4, p<0.0001)$

Similarly, younger children were more likely to be struck at areas of the street where there were no traffic controls. Older children were more likely to be struck where traffic controls were present. These differences are presented in Figure 7, and were statistically significant. $\left(X^{2}=1197.472 \quad \mathrm{df}=6 \quad \mathrm{p}<0.0001\right)$

There are, again, differences between the age groups in the importance of pedestrian actions that precede crashes. Table 3 shows the importance of emerging from between parked cars for the younger age group as well as greater reference to "playing in the roadway". There was a notable lack of injuries occurring when exiting or entering school buses.

\section{Road and Weather Conditions}

The character of the road upon which pedestrian accidents occurred did not change appreciably across age groups. The majority (85\%) were level for all age groups. Only about $7 \%$ of incidents occurred on roads that had a grade or hill at the area of the accident. The road character was unknown for the remaining $8 \%$ of cases. Table 4 presents the proportion of incidents in which wet road surfaces were present. Table 5 presents weather conditions at the time of the crashes.

\section{Driver Actions}

The majority of crashes occurred as drivers were going straight on the road, although the oldest pediatric group was at a relatively larger risk of being struck 
while a driver was turning (particularly left turns) or backing/parking. $\left(X^{2}=\right.$ $1016.459 \mathrm{df}=10 \mathrm{p}<0.0001)$ These results may be found in Table 6 .

\section{Injury Severity}

Injury severity, as ascertained by police personnel, was consistent across age groups. Overall, approximately one half of one percent of injuries resulted in death. There was a slight but perceptible increase in proportion of fatalities and severe injuries among the oldest pedestrians (Table 7 ). These differences were statistically significant $\left(X^{2}=173.479 \mathrm{df}=6 p<0.0001\right)$. In Figure 8 fatalities are grouped with severely injured pedestrians. This categorization to test for the effect of age failed to achieve statistical significance. 


\section{DISCUSSION}

The injury rate of $245 / 100,000$ is higher than that reported by previous authors. In areas of New York City from 1989 to 1995, an estimated 127/100,000 pediatric population was reported to suffer severe pedestrian injury. ${ }^{5}$ A pediatric injury rate of $138 / 100,00$ for pedestrians under the age of 14 was reported in Memphis, Tennessee ${ }^{16}$. The higher rate reported here reflects, in part, that the police data was more inclusive than that found in hospital-based studies, although it may also reflect that many of the injured children that make up the numerator of the rate may be tourists or other non-residents who are not included in the denominator. The results, though, are similar to a 1991 Hartford, Connecticut study of pediatric pedestrians under the age of 20 that reported a child pedestrian injury rate of $228 / 100,000 .{ }^{17}$

The case fatality rates reported are lower than those cited by other authors. ${ }^{1}$ Again, this reflects the comprehensive nature of the data. The inclusion of the many minor injuries documented by the police drives down the case-fatality rate.

The overall decline in the number of pedestrian injuries and fatalities in New York City during the study period mirrors the results of other investigators ${ }^{18}$, although the decline was not so steep as previously reported. That the decline was limited to the 5 to 14 year olds has not been reported. As Roberts has hypothesized, some of this decrease may be attributed to less walking ${ }^{18}$; perhaps 5 to 14 year olds make greater use of public transportation, school buses or rides from parents than the older pediatric group does.

The greater frequency of injuries occurring on weekdays is contrary to Baker's report ${ }^{19}$ that most injuries, including motor vehicle crashes, occur on weekends. That this increased risk was limited to months when school is usually in session, prompts the hypothesis that the increased weekday risk is mediated by schoolrelated travel. While there was some evidence that this is the case for 10 to 14 year olds, this is an area for further analysis.

The occurrence of injuries at intersections is an interesting variable that highlights the differences between the younger and older pediatric pedestrians, differences that were seen consistently across all variables. For example, while it has been reported that $78 \%$ of pedestrians struck in New York City were at intersection crosswalks, ${ }^{20}$ for the youngest pedestrians in this study, most injuries occurred midblock. This may reflect the "dart and dash" type of injury described by Preusser. ${ }^{21}$

The results for "pedestrian action" again show the importance of midblock injuries for the youngest pedestrians as opposed to intersection-based injury occurrence for the oldest children. And, the results for driver maneuvers were generally consistent with midblock injuries among the youngest pedestrians. These results were consistent with the finding that the youngest children were also most 
sensitive to the lack of traffic controls (which are less likely to be found at midblock locations). In keeping with the urban nature of the study setting, few incidents involved a hill or road gradient contributing to injury occurrence; this variable was not closely analyzed.

It is intuitive to believe that wet road surfaces play an important role in the occurrence of pedestrian injuries, but the finding that over $78 \%$ of incidents road conditions were described as "dry" puts this to question. On average, New York City annually experiences 0.01 inches of precipitation on 121 (33\%) days each year. ${ }^{22}$ There were therefore fewer than expected crashes during inclement weather.

Since older children were at increased risk of injury during inclement weather, perhaps the younger children are more likely to be at home or under greater supervision during bad weather. Also, while the proportion of injuries occurring when entering or exiting school buses is small, it remains a readily identifiable and important area for prevention.

The lack of difference in injury severity between the age groups is perhaps surprising given the differences found for other variables. Any statistical significance found in injury severity by age group was mostly a function of the large sample size. Given the large sample size, that the chi-square analysis of a dichotomized version of this variable (fatal / severe injuries vs. moderate / minor injuries) did not achieve statistical significance was notable.

The findings have implications for planning, prevention programs and services. There are more pediatric pedestrian injuries in the summer. School-based prevention programs should not be limited to the school year. During these vacation months, emergency departments should assure adequate and appropriate staffing, such as Advanced Trauma Life Support trained emergency physicians with pediatric surgical consults on call. Emergency medical transportation services need to be appraised of those departments that are prepared to accept injured pediatric pedestrians.

That most injuries to 5 to 9 year olds are injured in the middle of blocks indicates the role of street play in the occurrence of these injuries. Prevention programs should not only stress the dangers of street play, but also provide alternatives, such as organized activities in playgrounds. Trauma services, through the work of coordinators and clinicians, are ideal partners for community groups in addressing the needs of their communities in this respect. 


\section{LIMITATIONS AND FUTURE QUESTIONS}

The denominator for the injury rates was based on census bureau figures. Certain areas of the city, particularly in Manhattan, have high transient populations of commuting workers and tourists. Not all the injured pedestrians included in the numerator of the rates may have been represented in the denominator. Some rate stabilization is to be expected over the course of 7 years, and rates are presented only for the larger and more stable geographic area of the city as a whole, but the rates should be interpreted with this possible bias in mind.

Children under the age of 5 posed a difficulty in this study. These children are frequently injured in so-called "roll overs" that occur on private driveways ${ }^{23}$. The data are limited to pedestrian injuries on public roadways and do not include private driveways. These results probably underestimate injuries to small children and toddlers. Adding to the difficulty, some variables for this age group were missing entries for nearly $30 \%$ of cases. No results were reported for those variables.

Ratings of Injury severity in this study must be interpreted cautiously. Nonmedical personnel made the determinations. The accuracy of police assessments has been called into question. ${ }^{24}$ Cosmetically impressive but nonlife threatening wounds such as "severe lacerations" might be included in the "Severe" categorically, while a less apparent solid viscous injury might be placed in a lesser category. The designations are useful as an estimate of injury severity, but are far from precise assessments. Linkage to hospital records would be necessary to achieve a truly valid measurement of injury severity.

Fatalities may also be misleading. Determinations of fatality were based on assessments performed at the scene of the crash. They do not capture subsequent deaths in the emergency department or after hospitalization. It should be expected that some percentage of those categorized as severely injured would subsequently succumb to their injuries. The case-fatality rate is in all likelihood an underestimate. It was hoped that categorizing into fatal / severe injuries would group together fatalities with some of the subsequent deaths as well as with those injuries that were potentially life threatening.

Despite these limitations, these results complement those based on medically treated or fatal injuries by capturing the full range of pedestrian injuries. They hep present a more complete picture of pediatric pedestrian injury occurrence in an urban setting.

The results also raise questions for future research. Such routinely gathered, governmental sources of data constitute an important resource for researchers. Governmental- academic collaborations to analyze this type of data should be encouraged. Studies of the accuracy and completeness of police recording of 
injury severity and the circumstances surrounding the occurrence of injury would be necessary. Linkage of police reports to clinical data sources such as trauma registries would perhaps be the best approach to improving the quality of data. Geographic information systems would be an excellent means of presenting data and analyzing results. The role of drivers, vehicle factors and pedestrian behaviors all deserve attention. 


\section{CONCLUSIONS}

This descriptive study illustrates how the epidemiology of pediatric pedestrian injury differs by age group and fluctuates temporally. These results indicate that different behaviors are at play as well as different exposure opportunities. The youngest pedestrians appear to be more sensitive to risks posed by their environment as measured by such variables as presence or absence of traffic controls and pedestrian actions prior to injury. One methodological lesson from this study it is the importance of making investigations or interventions into pediatric pedestrian injuries age specific. Another lesson is the use to which routinely collected data can be put to describe patterns of injury. 


\section{TABLES AND GRAPHS}

Table 1: Age-specific yearly pediatric pedestrian injury, fatality and case-fatality rates, New York City 1991-1997:

\begin{tabular}{l|l|l|l}
\hline Age Group & $\begin{array}{l}\text { Injury Rate (per } \\
100,000)\end{array}$ & $\begin{array}{l}\text { Fatality Rate (per } \\
100,000)\end{array}$ & Case Fatality (\%) \\
\hline$<5$ & 92.9 & 0.9 & 1.0 \\
\hline 5 to 9 & 333.1 & 1.6 & 0.5 \\
10 to 14 & 355.2 & 1.3 & 0.4 \\
15 to 19 & 220.9 & 1.7 & 0.8 \\
Total (1 to 19$)$ & 245.4 & 1.4 & 0.6 \\
\hline
\end{tabular}

Figure 1: Yearly Frequency of Pediatric Pedestrian Injury by Age Group, New York City 1991 to 1997

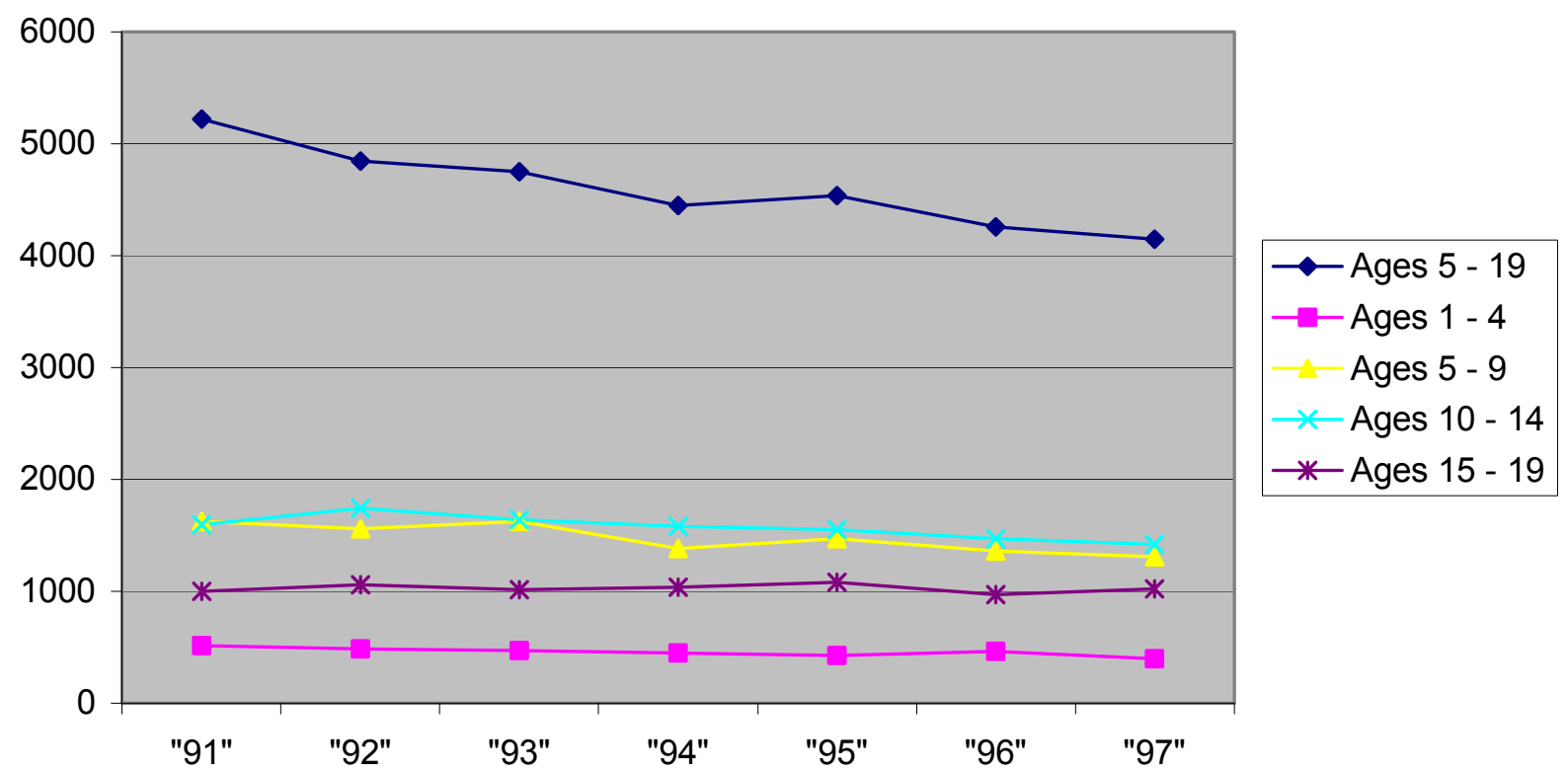


Figure 2: Percentage of Pediatric Pedestrian Injuries by Month and Age Group, New York City, 1991-1997

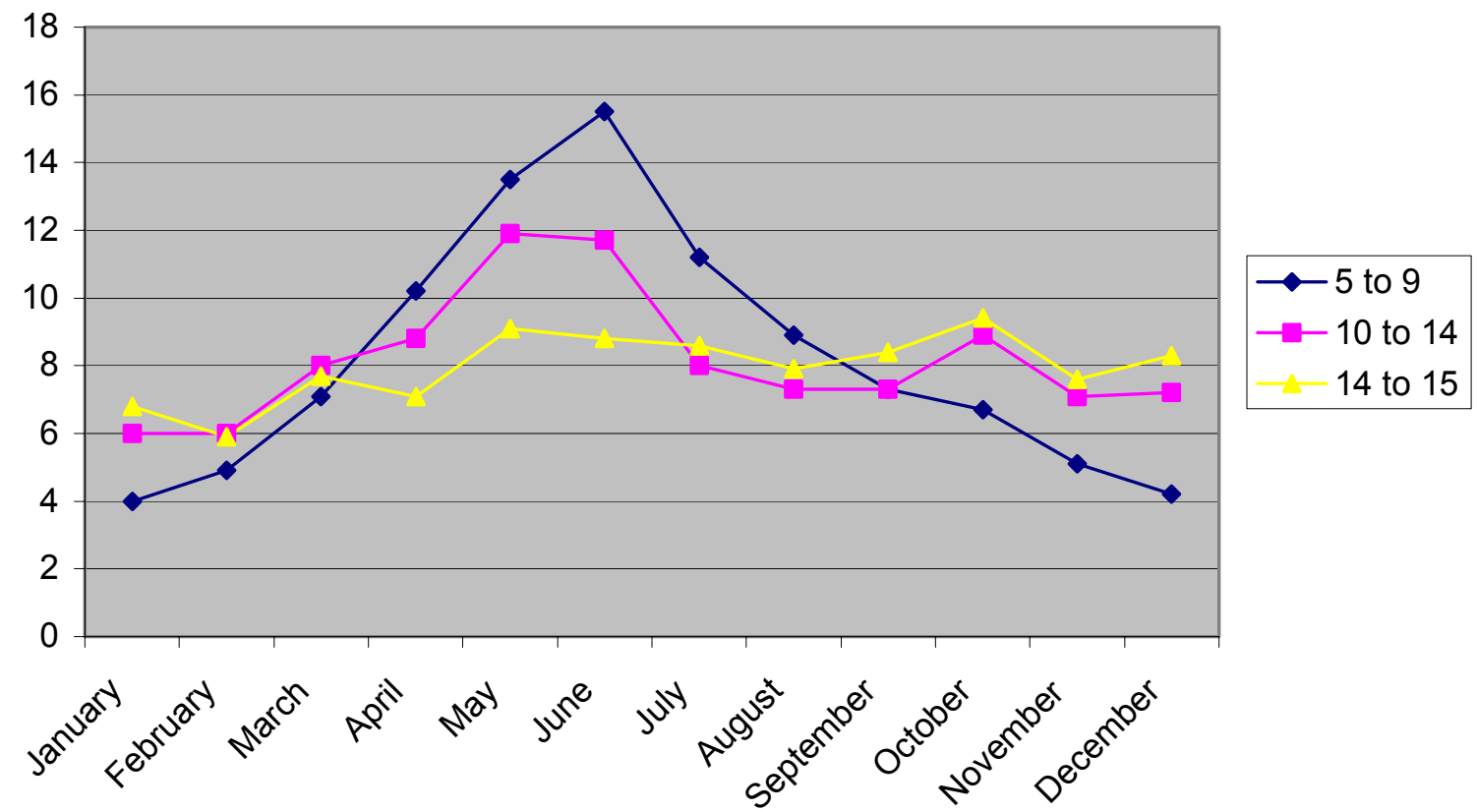

Table 2: Number and Percent of Injuries by Day of Week

1 to 4 Years Old 5 to 9 Years Old 10 to 14Years Old 15 to 19 Years Old

Day of Frequen Percent Frequency Percent Frequency Perce Frequency Percent

Week cy

Sunday 420

Monday 331

Tuesday 344

Wednesday 287

Thursday $\quad 351$

Friday 420

Saturday 464

$12.7 \quad 1115$

10.6

1015

nt

$10.0 \quad 1325$

$12.6 \quad 1524$

9.1

686

1021

9.1

$10.4 \quad 1349$

$12.9 \quad 1718$

13.6

1058

$13.3 \quad 1650$

15.3

8.6

1390

14.4

1563

12.7

1505

16.2

14.7

1011

$14.0 \quad 1035$

13.5

14.0

1700

13.8

17.3

1186

13.4

14.0

1444

1940

11.0

913

$\begin{array}{llll}6.2 & 558 & 5.0 & 628\end{array}$

13.7

15.7

12.1

$21.2 \quad 651$

8.3 
Figure 3: Monthly Percentage of Pediatric Pedestrian Injuries Occurring on Weekends by Age Group, New York City, 1991-1997

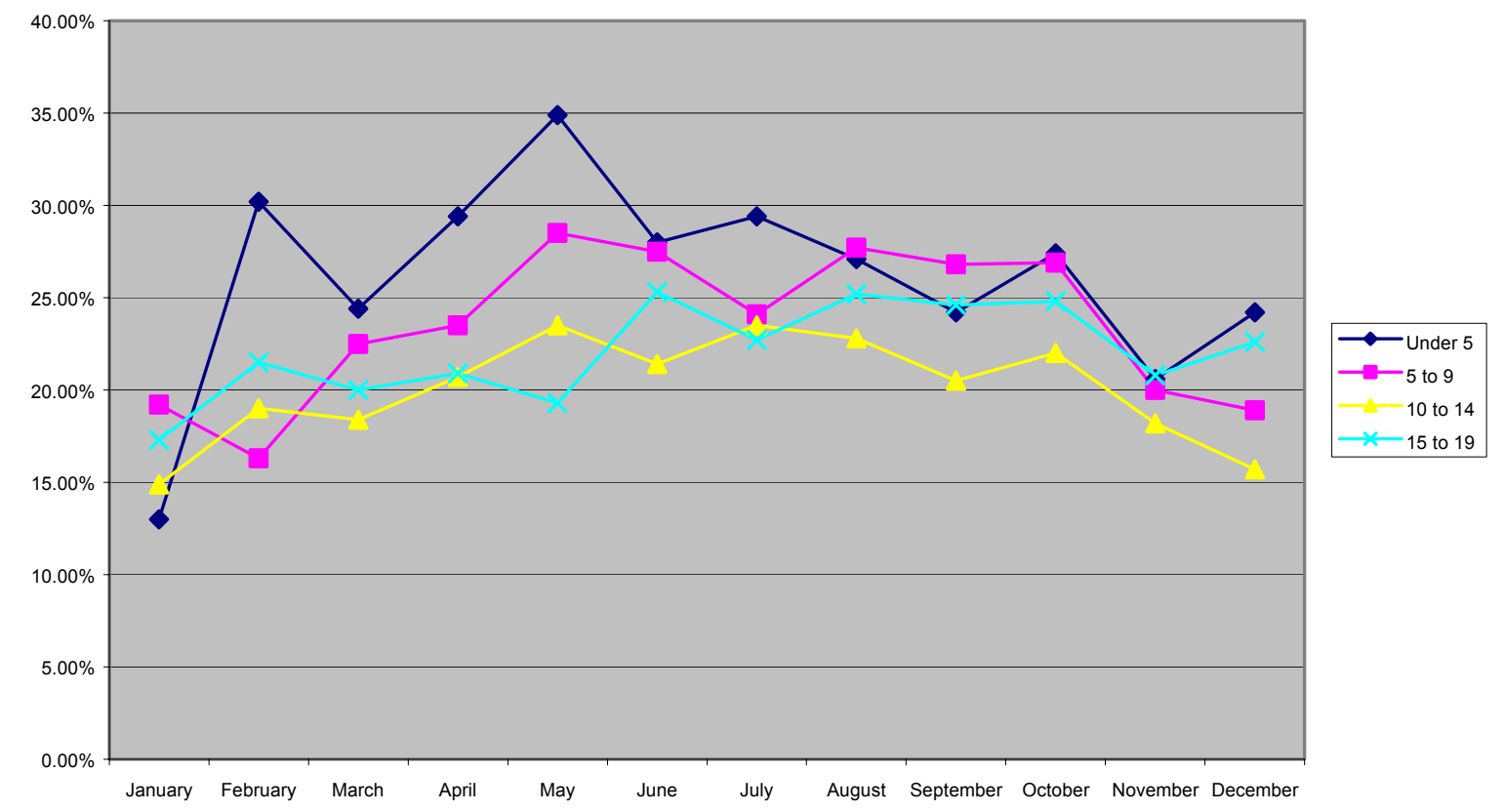

Figure 4: Age Frequencies of Injured Pediatric Pedestrians, New York City, 1991-1997.

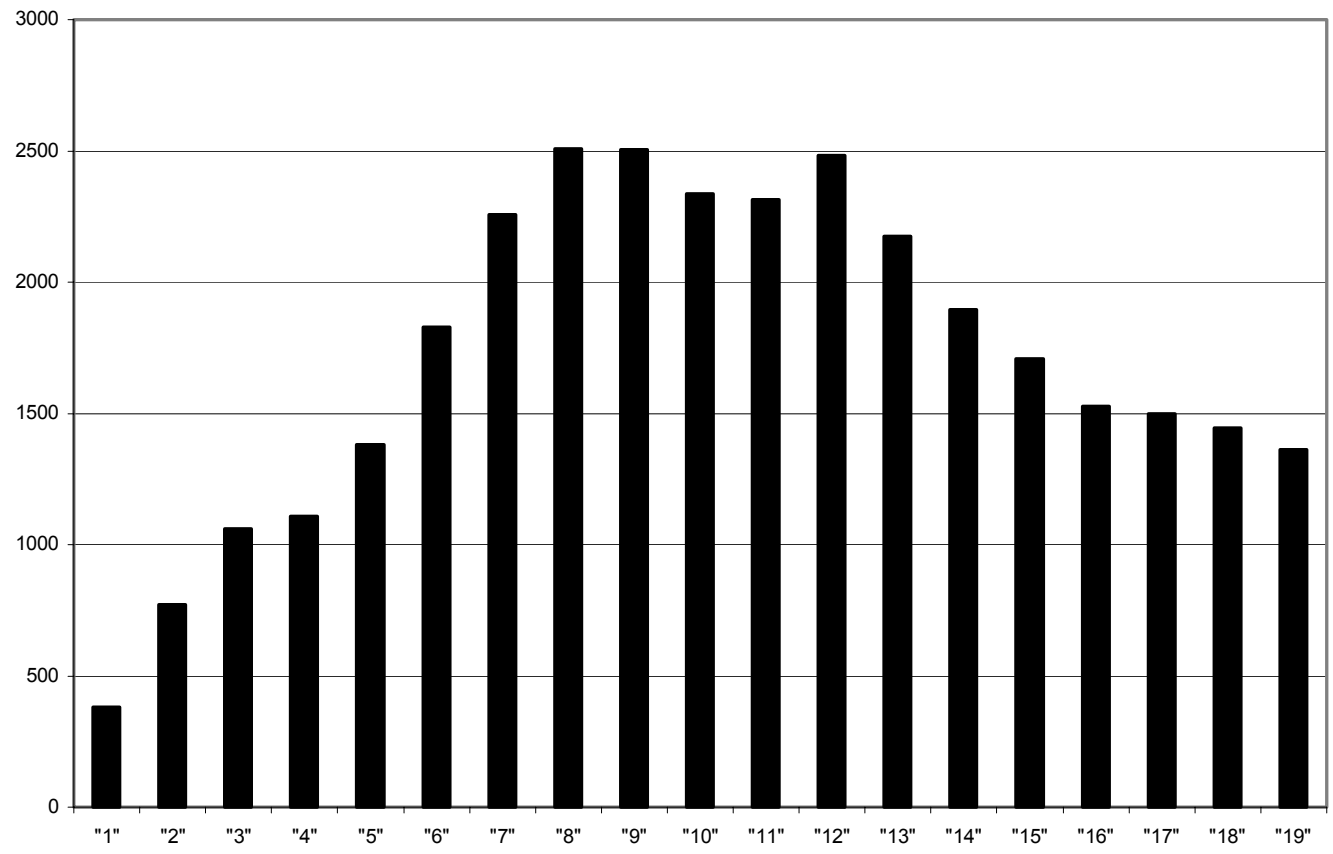


Figure 5: Proportion of Pediatric Pedestrian Injuries by Gender and Age Group, NYC 19911997

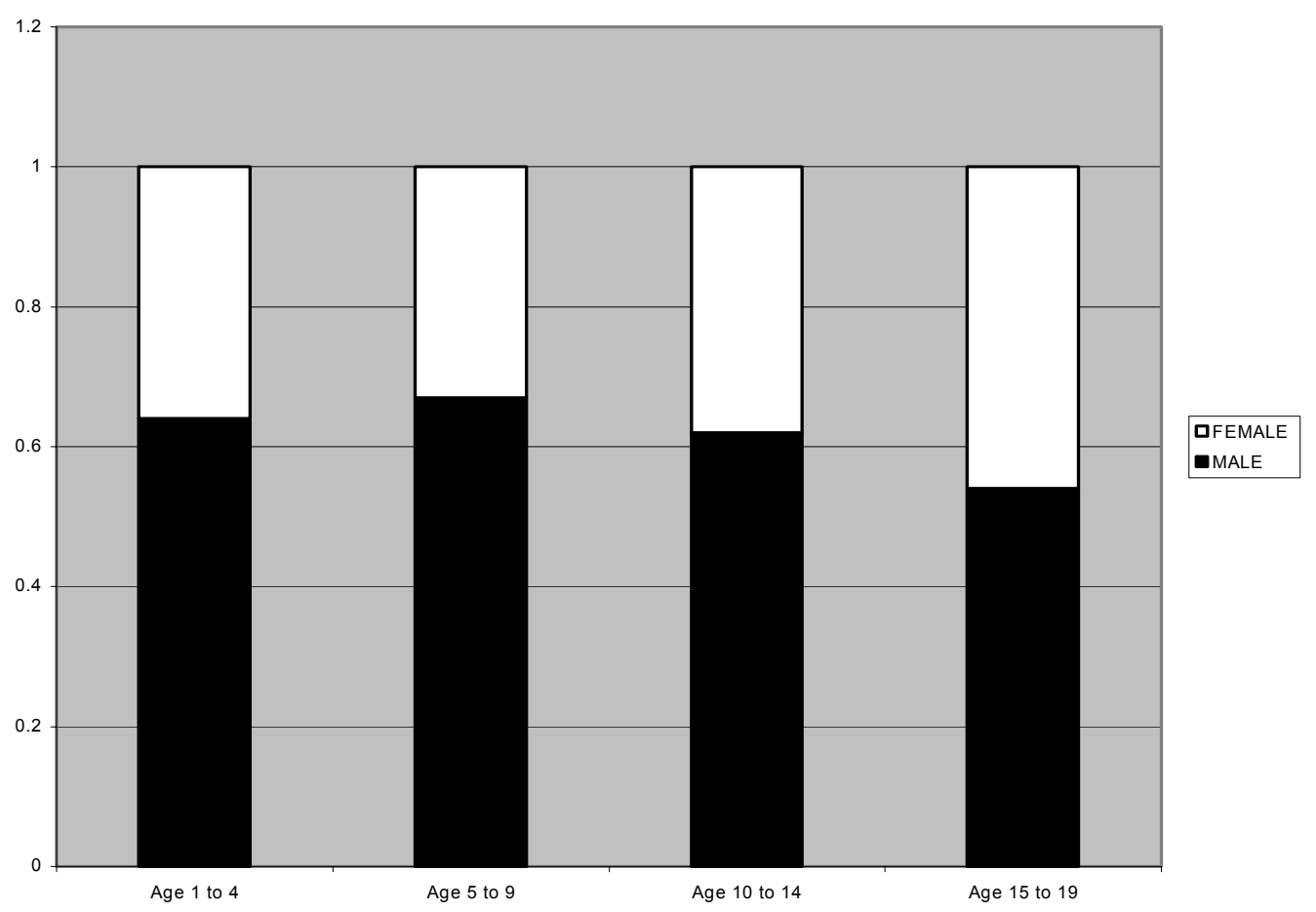

Figure 6: Proportion of Pediatric Pedestrian Incidents Occurring at Intersections, New York City, 1991-1997

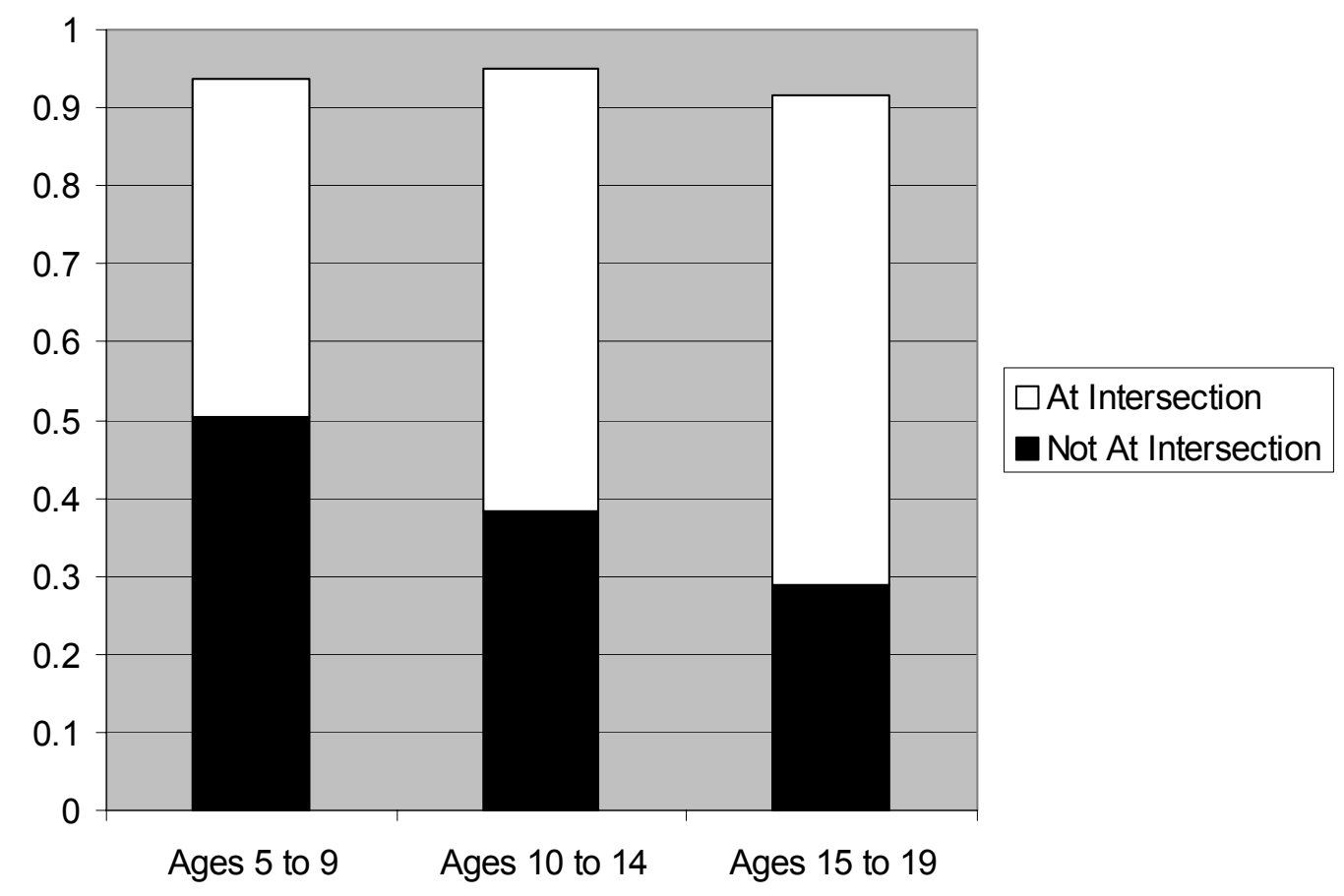


Figure 7: Proportion of Pediatric Pedestrian Incidents Occurring at Sites with Traffic Controls, New York City, 1991-1997

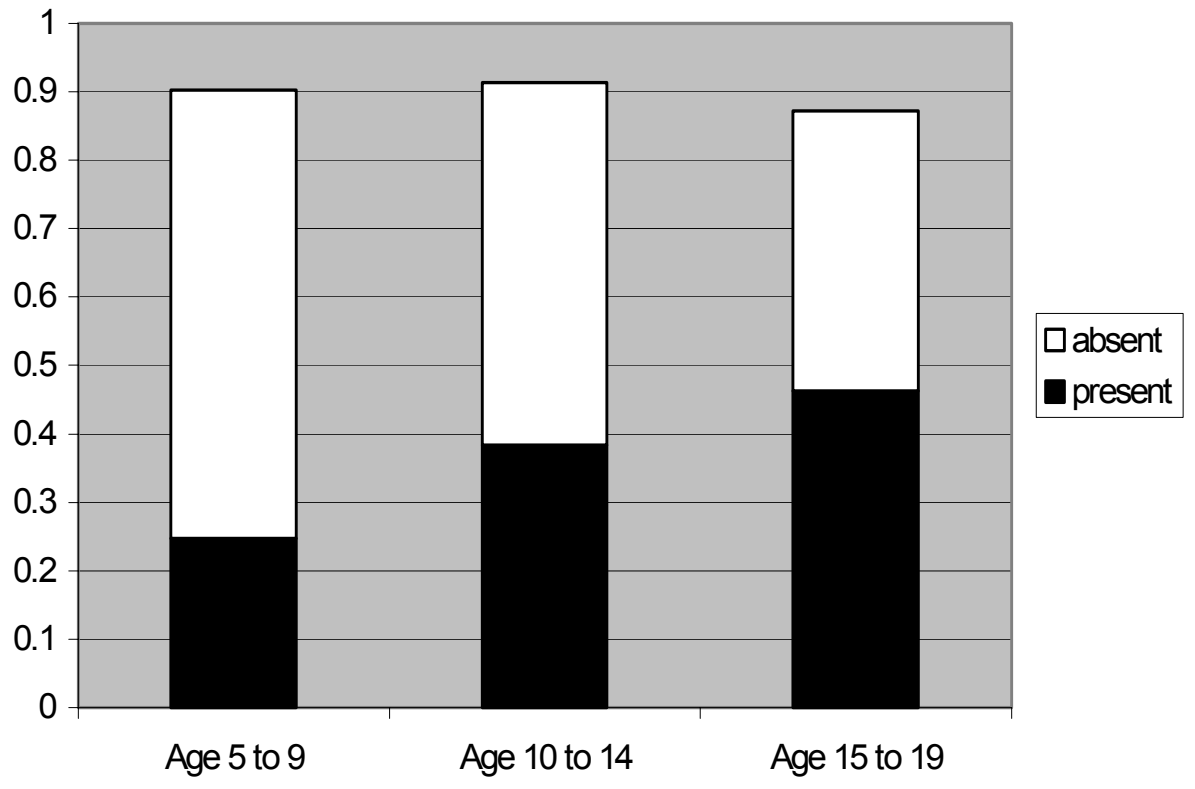

Table 3: Pediatric Pedestrian Actions Preceding Crashes, NYC 1991-1997

\begin{tabular}{l|rrr}
\hline \multicolumn{1}{c|}{$A G E$} & 5 to 9 & 10 to 14 & 15 to 19 \\
\hline & Percent & Percent & Percent \\
crossing with signal & 7.3 & 13.1 & 19.1 \\
crossing against signal & 10.6 & 15.0 & 14.2 \\
crossing, no signal, marked crossway & 5.6 & 5.6 & 5.5 \\
crossing, no signal or crosswalk & 28.0 & 23.7 & 19.7 \\
walking along highway with traffic & .2 & .7 & 1.4 \\
walking along highway against traffic & .2 & .3 & .5 \\
emerging from in front of / behind parked vehicle & 20.6 & 13.1 & 6.5 \\
going to or from stopped school bus & .6 & .3 & .2 \\
getting on or off vehicle other than school bus & .6 & .9 & 1.7 \\
pushing / working on car & .0 & .1 & .1 \\
working in roadway & .2 & .2 & .3 \\
playing in roadway & 7.8 & 7.1 & 2.8 \\
other actions in roadway & 5.0 & 6.3 & 7.8 \\
not in roadway & 1.1 & 1.4 & 2.6 \\
unknown & 12.2 & 12.3 & 17.4 \\
Total & 100.0 & 100.0 & 100.0 \\
\hline
\end{tabular}


Table 4: Road Surface Conditions (Percent) Preceding Pediatric Pedestrian Actions, NYC 1991-1997

\begin{tabular}{l|lll}
\hline & Age 5 - 9 & Age 10 - 14 & Age 15-19 \\
\hline Dry & 81.5 & 79.3 & 73.2 \\
Wet & 11.2 & 14.4 & 16.7 \\
Unknown & 7.3 & 6.4 & 10.1 \\
\hline
\end{tabular}

Table 5: Weather Conditions (Percent) at time of Pediatric Pedestrian Injury, NYC 19911997

\begin{tabular}{l|lll}
\hline & Age 5 - 9 & Age 10 - 14 & Age 15-19 \\
\hline Clear & 74.1 & 71.5 & 66.2 \\
Cloudy & 12.4 & 13.2 & 11.7 \\
Rain/Snow/Sleet/Fog & 6.2 & 9.0 & 12.1 \\
Other / Unknown & 7.4 & 6.3 & 10.0 \\
\hline
\end{tabular}

Table 6: Driver Actions Preceding Pediatric Pedestrian Injury, NYC 1991-1997

\begin{tabular}{l|rrr}
\hline \multicolumn{1}{c|}{$A G E$} & 5 to 9 & 10 to 14 & 15 to 19 \\
\hline & Percent & Percent & Percent \\
going straight & 82.3 & 78.2 & 63.5 \\
right turn & 1.9 & 3.3 & 5.5 \\
left turn & 2.5 & 4.0 & 7.8 \\
backing / parking & 2.1 & 3.1 & 5.4 \\
other & 3.5 & 4.3 & 6.5 \\
unknown & 7.8 & 7.2 & 11.2 \\
Total & 100.0 & 100.0 & 100.0 \\
\hline
\end{tabular}

Table 7: Number (Percent) Pediatric Pedestrian Injury Severity, NYC 1991-1997:

\begin{tabular}{r|r|rrr}
\hline & Age 1 to 4 & Age 5 to 9 & Age 10 to 14 & Age 15 to 19 \\
\hline Killed & $32(0.9)$ & $50(0.5)$ & $43(0.4)$ & $56(0.7)$ \\
Severe & $466(14.0)$ & $1463(14.0)$ & $1639(14.6)$ & $1253(16.6)$ \\
Moderate & $1026(30.9)$ & $3034(29.0)$ & $2685(24)$ & $1591(21.1)$ \\
Mild or None & $1796(54.0)$ & $5932(56.6)$ & $6833(61)$ & $4638(61.5)$ \\
Total & $3320(100)$ & $10479(100)$ & $11200(100)$ & $7538(100)$ \\
\hline
\end{tabular}


Figure 8: Dichotomized Injury Severity, Pediatric Pedestrian Injuries, New York City 19911997

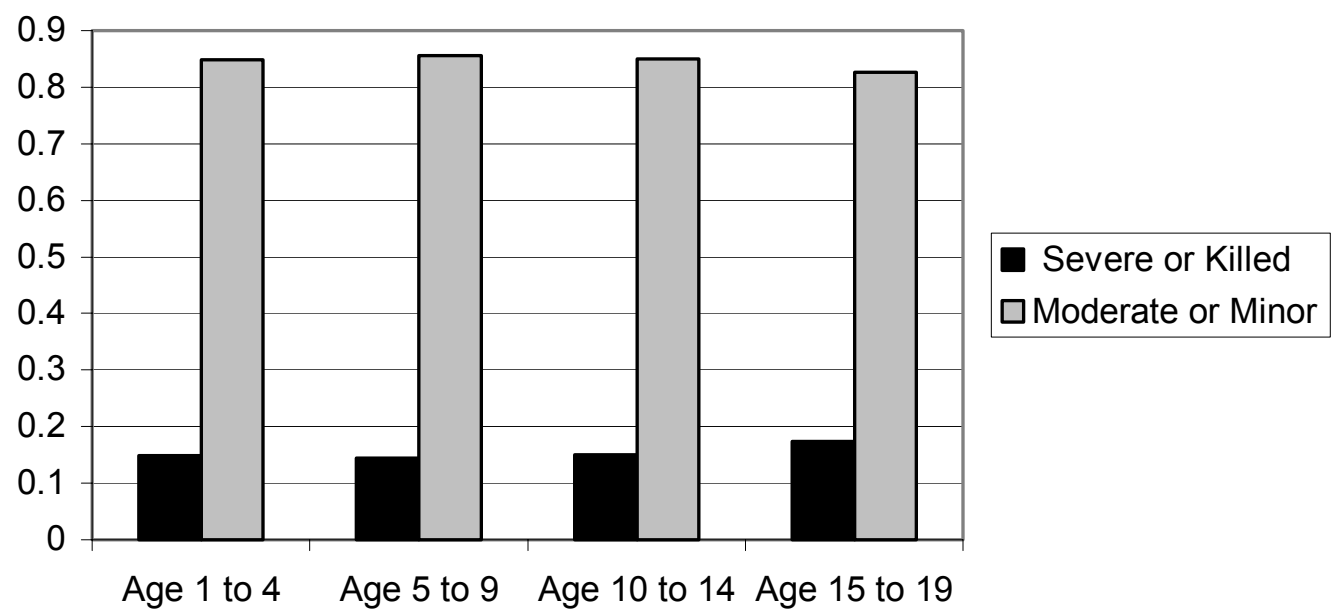




\section{REFERENCES}

${ }^{1}$ Rivara FP. Child pedestrian injuries in the United States: current status of the problem, potential interventions, and future research needs. Am J Dis Child 1990; 144 (6): 692-6.

${ }^{2}$ Insurance Institute for Highway Safety Website. http://www.iihs.org

${ }^{3}$ Roberts I, Norton R, Jackson R, Dunn R, and Hassall I. Effect of environmental factors on risk of injury of child pedestrians by motor vehicles: a case-control study. BMJ 1995; 310 (1): 91-4.

${ }^{4}$ National Safety Council. Accident Facts: 1997 Edition. National Safety Council, Itasca Il, 1998. p 30.

${ }^{5}$ Durkin MS. Laraque D. Lubman I. and Barlow B. Epidemiology and prevention of severe traffic injuries to children in an urban community. (personal communication / manuscript)

${ }^{6}$ Roberts I., Streat S, Judson J, and Norton R. Critical injuries in pediatric pedestrians.

NZ Med J. 1991; 104: 247 - 8.

${ }^{7}$ Wazana A, Krueger P, Raina P, and Chambers L. A review of risk factors for child pedestrian injuries: are they modifiable? Inj Prev. 1997 Dec; 3(4): 295-304.

${ }^{8}$ Routledge DA, Repetto-Wright R, and Howarth CI. The exposure of young children to accident risk as pedestrians. Inj Prev. 1996 Jun; 2(2): 150-161

${ }^{9}$ Durkin M, Olsen S, Barlow B, Virella A, and Connolly ES. The epidemiology of urban pediatric neurological trauma: evaluation of and implications for injury preventions programs. Neurosurgery. 1998; 42 (2): 300-310.

${ }^{10}$ Retting RA. Urban pedestrian safety. Bull N Y Academy Med. 1988; 64 (7): $810-815$

${ }^{11}$ State of New York Department of Motor Vehicles. Police Accident Report (MV-104A/AN). Albany, NY, Date not listed.

${ }^{12}$ National Highway Traffic Safety Administration. FARS Analytic Reference Guide 1975 to 1997. Department of Transportation, Washington DC. 1997.

${ }^{13}$ State of New York Department of Motor Vehicles. Summary of Motor Vehicle Accidents: New York City. Albany, NY: January 1997.

${ }^{14}$ USD Inc. Epidemiology Info Version 6.04. Stone Mountain, Ga. 1997.

${ }^{15}$ SPSS Inc. SPSS Base 9.0 User's Guide. Chicago, Ill. 1999.

${ }^{16}$ Roberts I. Why have child pedestrian rates fallen? BMJ 1993; 306 (6): 1737-9.

${ }^{17}$ Lapidis G, Braddock M, Banco L, Mentenegro L, Hight D, and Eanniello V. Child pedestrian injury: a population collision and injury severity profile. J Trauma 1991; 31 (8): 1110-1115.

18 . Roberts I. Why have child pedestrian death rates fallen? BMJ. 1993; 306 (6): 1737-9.

${ }^{19}$ Baker SP, O’Neill B, Ginsburg MJ and Guohua L. The Injury Fact Book. $2^{\text {nd }}$ ed. New York, NY: Oxford; 1992:

${ }^{20}$ Silver H. NYC Traffic Facts. http://www.citystreets.org/html/press/press_03.html. Accessed 43/2000.

${ }^{21}$ Preusser DF. Reducing pedestrian crashes among children. Bull N Y Acad Med. 1988; 64(7): 623-631. 
${ }^{22}$ Golden Gate Weather Services Comparative Climatic Data.

http://www.ggweather.com/ccd/pcrpdays.html. Accessed 9 January 2001.

${ }^{23}$ Brison RJ, Wicklund K, and Mueller BA (1988) Fatal pedetrian injuries to young children: a different pattern of injury. Am J Public Health 78 (7): 793-795.

${ }^{24}$ Brison RJ, Wicklund K, and Mueller BA (1988) Fatal pedetrian injuries to young children: a different pattern of injury. Am J Public Health 78 (7): 793-795. 